\title{
AC 2009-163: AN INTERDISCIPLINARY NUCLEAR POWER OPERATIONS COURSE CO-DEVELOPED WITH THE PALO VERDE NUCLEAR GENERATING STATION
}

Keith Holbert, Arizona State University

Jeffrey Goss, Arizona State University 


\title{
An Interdisciplinary Nuclear Power Operations Course Co-Developed With The Palo Verde Nuclear Generating Station
}

\begin{abstract}
The development of an entire online course on interdisciplinary nuclear power operations is described herein. This course is a unique industry-university team-taught course in cooperation with the Palo Verde Nuclear Generating Station (PVNGS), and is part of a new graduate-level certificate program in Nuclear Power Generation at Arizona State University. The course objective is to instill the fundamental concepts and importance of nuclear safety to engineers and scientists in a variety of disciplines. The course content and lessons learned are reported.
\end{abstract}

\section{Introduction}

The U.S. Congress and the Nuclear Regulatory Commission (NRC) have recognized that the United States is at the onset of a nuclear power renaissance. As of December 2008, the NRC has received 17 applications for construction and operating license (COL) applications for a total of 26 reactors; current expectations are that the NRC will receive 6 more COL applications for an additional 9 reactors (for a total of 34 units) over the next two years ${ }^{1,2}$. This revival in nuclear power plant construction is being spurred by increased electricity demands and the incentives in the Energy Policy Act of $2005^{3}$ as well as concerns about greenhouse gas emissions and reliance on foreign energy resources. As NRC Chairman Dale Klein has noted, the nuclear workforce is graying, and the NRC is poised to hire hundreds of new employees in preparation for the expanded workload, including the staffing of the recently added Office of New Reactors ${ }^{4}$. Others have also noted the staffing shortfalls in the nuclear industry ${ }^{5}$ as well as the electric power industry in general. In fact, estimates are that $50 \%$ of the utility engineering workforce will retire within 10 years ${ }^{6}$.

In recognition of the nuclear revival, the NRC initiated a grant program to support the educational infrastructure necessary for the nation to safely move forward with its nuclear energy initiatives. The NRC is funding the development of a new course at Arizona State University (ASU) in cooperation with the Palo Verde Nuclear Generating Station (PVNGS) - the nation's largest nuclear power plant. PVNGS was also one of the last nuclear plants to be constructed in the U.S., and therefore has some of the more modern facilities in operation. This unique industry-university team-taught course focuses on Interdisciplinary Nuclear Power Operations. The course draws upon the expertise of plant personnel in dealing with day-to-day operations, whereas faculty are more accustomed and adept at classroom teaching and educational pedagogy. As a distinctive course for which lecture materials must be developed, the plant personnel are assuming the lead on enumerating and detailing the critical topics and information to be covered. University faculty are then converting the experiential knowledge into suitable classroom materials, including exercises, case studies, design projects, etc., and ensuring that the requisite academic rigor is present. To create real-life examples that are integrated into the online content, video footage is shot at PVNGS, edited in production studios at ASU, and then packaged as distributed media for synchronous and asynchronous online delivery. 
A major course aim is the study of the interrelationship and propagation of effects that systems and design changes have on one another, especially in relation to nuclear power plant safety and operations. The interdisciplinary nature of the nuclear power plant operations course provides the capability to educate engineers and scientists in a variety of fields. Consequently, the extension of the course audience to a wide variety of majors serves to insure that the nuclear power industry workforce is poised to conduct operations in a safe, secure and environmentally sound manner.

\section{The Nuclear Power Generation Graduate Certificate}

The course being developed is a component of the Nuclear Power Generation (NPG) graduatelevel certificate program that has been initiated at ASU. The courses of this program are designed to be taken by students from all engineering disciplines and other sciences (e.g., physics, chemistry and mathematics). The courses are offered on-campus and simultaneously recorded to streaming video for distance-learning via the Internet. The Fulton School of Engineering presently delivers over 100 online courses annually to thousands of students across the U.S. and beyond. We also anticipate the opportunity to partner with other institutions to distribute these course materials to fill gaps in nuclear and other engineering programs nationwide. Beside online delivery, the course video and documentation can be packaged in DVD format for dissemination to such audiences.

Part of the rationale for a professional certificate program is that an entire graduate, for example Masters, degree is unnecessary to position an individual to work effectively in the nuclear industry. At ASU, a graduate certificate is a programmatic or linked series of courses in a single field or in a field that crosses disciplinary boundaries. Graduate certificates facilitate the professional growth for people who already hold the baccalaureate degree. Unlike more extensive graduate programs that provide candidates with research skills for a profession in academe or industry, graduate certificates offer candidates an opportunity for growth in their present field of employment, an opportunity to try out a new field in which they may ultimately complete a graduate degree, or an opportunity for personal enrichment. Specifically, online students can take the courses listed here without being enrolled in a particular degree program, that is, an engineer who feels that only a subset of the offered courses fulfills her/his needs can benefit from the course development proposed in this project.

The Nuclear Power Generation graduate certificate is a new multidisciplinary professional option within the Fulton School of Engineering. A present shortcoming of post-baccalaureate nuclear engineering related courses is that the majority assume an undergraduate education in nuclear engineering. Furthermore, we recognize that the majority of engineers working at and in support of nuclear plant operations are not nuclear engineers. Such circumstances should compel higher educational institutions to offer courses that instill the fundamental concepts and importance of nuclear safety to engineers and scientists in a variety of disciplines. Moreover, engineers who already have degrees, recent or somewhat dated, should not need to begin with introductory nuclear engineering courses, typically taught at a sophomore level, but rather these engineers require an understanding of the essentials of the interrelationship between the nuclear and thermal-hydraulic processes along with basic knowledge of nuclear power plants and their safety 
systems, especially the systems related to the new Generation III plants proposed for construction in the U.S. over the next decade.

The graduate-level certificate program requires 18 semester hours of coursework (i.e., six 3-hr classes) with at minimum of two-thirds at the 500-level or higher. The following 3-hr courses (also see Figure 1) are presently listed within the professional certificate program (with some categorized as core courses and others as electives):

\section{Core courses}

- Structural Materials in Nuclear Power Systems

- Reactor Theory and Design

- Reactor System Dynamics and Controls

- Interdisciplinary Nuclear Power Operations (the course being reported herein) Elective classes

- Nuclear Power Engineering - nuclear science and engineering fundamentals

- Electrical Power Plants

- Radiation Effects on Electronics

- Human Factors Engineering

- Sustainable Energy and Material Use

- Health Physics

- Fracture, Fatigue, and Creep

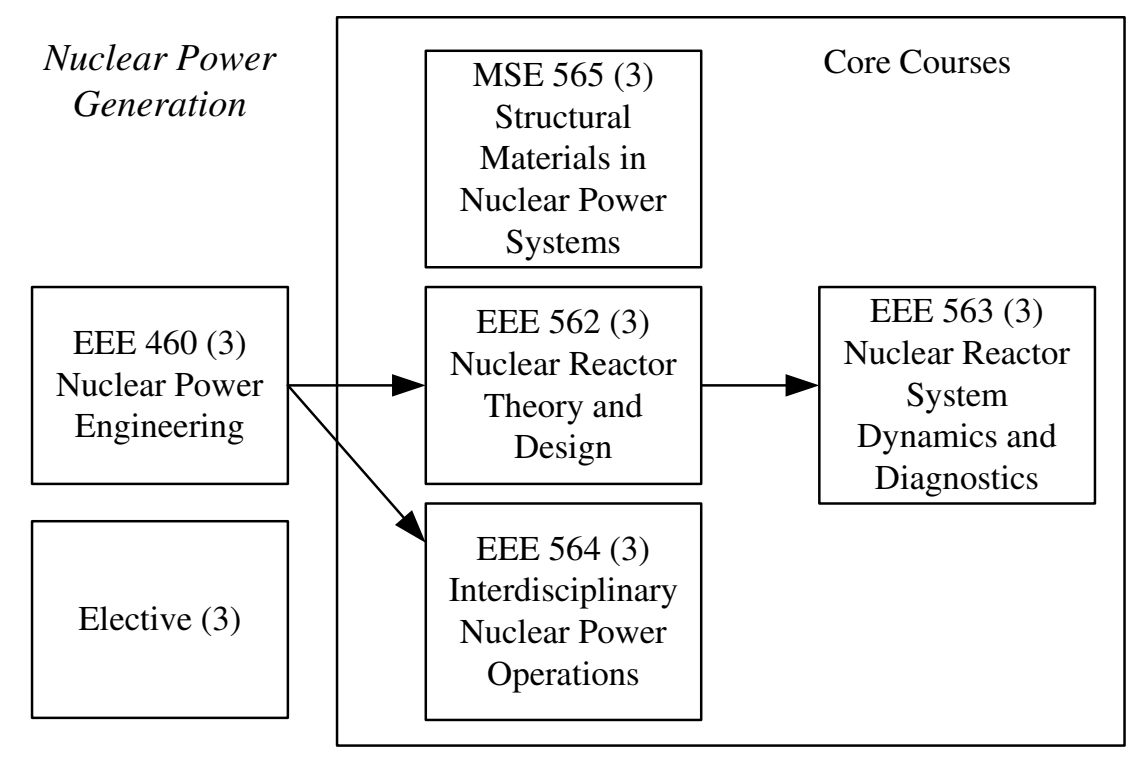

Figure 1. Nuclear Power Generation coursework.

Most, if not all, of the above courses would be available online. A few of these classes are at the undergraduate level such that senior students in all the engineering disciplines can take 1 or 2 courses prior to graduation, and still have enough courses remaining to complete the graduate- 
level certificate program. Furthermore, for those who do wish to pursue a graduate degree, they are generally more inclined to pursue an advanced degree in the same discipline for which they earned an undergraduate degree, and the credits earned for this graduate certificate could be applied to, for instance, the 30 hours required for a Masters degree in their particular major field of study.

It is important to note that these courses and the certificate program were designed not only to be accessible by students in a variety of fields, but also for the purpose of retraining (mid-career) engineers whose experience in other industries could be applied within the nuclear power industry. With the expectation that a large number of engineering positions will be created within the NRC, electric utilities and engineering-architect firms, it behooves the nuclear industry to seek out experienced as well as entry-level engineers in staffing decisions. The thought of having a vast majority of the new hires be freshly graduating students could be disconcerting to the public.

\section{The Course}

The formation of an entirely new and exclusively online course centered on interdisciplinary nuclear power plant operations is now addressed.

Industry is ripe with competent engineers with a wealth of experience. We are leveraging the university-industry cooperation between ASU and the Palo Verde Nuclear Generating Station (PVNGS) - the nation's largest nuclear power plant. PVNGS was also one of the last nuclear plants to be constructed in the U.S. (operating since 1986-1988), and therefore has some of the more modern facilities in operation. In particular, PVNGS consists of three Combustion Engineering pressurized water reactors with a net electric output of $1336 \mathrm{MWe}$ each.

The Interdisciplinary Nuclear Power Operations course draws upon the expertise of plant personnel in dealing with day-to-day operations, whereas faculty are more accustomed and adept at classroom teaching and educational pedagogy. This course is designed to be a part of the core requirements of the nuclear power certificate program. The interdisciplinary viewpoint of the course provides analysis of the impacts that various engineering processes (changes and failures) across the entire power plant. This course addresses topics such as industry resources (e.g., INPO), standards and regulations.

As a unique course for which lecture materials must be developed, the plant personnel are assuming the lead on enumerating and detailing the critical topics and information to be covered. The university faculty are converting the experiential knowledge into suitable classroom materials, including exercises, case studies, design projects, etc., and are ensuring that the requisite academic rigor is present. To create real-life examples that are integrated into the online content, video footage is shot at PVNGS, edited in production studios at ASU, and then packaged as distributed media for synchronous and asynchronous online delivery. The first offering of the course is scheduled for academic year 2009-2010.

The course pre-requisites are fundamental knowledge and understanding of nuclear power engineering. The course objective is to instill the fundamental concepts and importance of 
nuclear safety to engineers and scientists in a variety of disciplines. The corresponding course outcomes are

- Students are knowledgeable about nuclear power plants and their safety systems;

- Students are cognizant of the critical role of that engineers have on the safe operation of a nuclear power plant; and

- Students are prepared for the impacts that various engineering processes (changes and failures) have across the entire power plant.

A syllabus for the semester is given in Table I to provide an overall view of the course. Each of the topics addressed in the course is briefly described below.

1. Nuclear Safety and Risk Overview - instills the fact that the basic objective of reactor safety is to prevent the release of radionuclides so that the operation of nuclear power plants does not contribute significantly to individual and societal health risks, and that the basic strategy to accomplish this is to prevent fuel overheating. The concept and quantification of risk are also presented.

2. Nuclear Power Plant Systems - provides an overview of traditional (Generation II) pressurized water reactors (PWRs) and boiling water reactors (BWRs) as well as the new Generation III plants viewed as most likely to be built in the U.S, including Westinghouse's AP1000, Toshiba's advanced boiling water reactor (ABWR), the GE Hitachi economic simplified boiling water reactor (ESBWR), Areva's evolutionary power reactor (U.S. EPR), and Mitsubishi's U.S. advanced pressurized water reactor (USAPWR). This topic is covered early in the semester so that each student begins with the knowledge necessary to understand the context of the systems and components applicable to nuclear plant operation.

Table I. Syllabus for Interdisciplinary Nuclear Power Operations course

\begin{tabular}{|c|l|}
\hline Week & Topic Description \\
\hline 1 & Nuclear Safety and Risk Overview \\
\hline 2 & Nuclear Power Plant Systems \\
\hline 3 & Licensing, Regulatory Issues, Standards \\
\hline 4 & Emergency Preparedness and Response \\
\hline 5 & Plant Emergency and Safety Systems \\
\hline 6 & Integrated Plant Operations \\
\hline 7 & Materials Corrosion, and Chemical and Volume Control \\
\hline 8 & Instrumentation and Controls \\
\hline 9 & Human Factors \\
\hline 10 & Plant Modifications \\
\hline 11 & Radioactive Waste Generation and Effluent Monitoring \\
\hline 12 & Industry Events \\
\hline 13 & Security \\
\hline 14 & Grid Disturbances \\
\hline 15 & Exams (midterm and final) \\
\hline
\end{tabular}


3. Licensing, Regulatory Issues, Standards - covers the role of organizations such as the Nuclear Regulatory Commission (NRC), the Institute of Nuclear Power Operations (INPO), the World Association of Nuclear Operators (WANO), standards organizations (ANSI, IEEE, ANS, ISA, ASME, ASTM); the one-step (10 CFR Part 52) licensing process; requirements for and need to update the plant safety analysis report; and quality assurance.

4. Emergency Preparedness and Response - addresses the procedures and plan for plant operations during emergencies, including those due to natural occurrences, as well as the NRC emergency classification levels. A current topic in this area is hostile action (terrorism) emergency preparedness.

5. Plant Emergency and Safety Systems - begins by examining the differences between inherent, passive and engineered (active) safety features. Plant safety systems from a high enough level to be applicable across all reactor vendors are then presented; this includes low-pressure and high-pressure emergency core cooling systems, containment isolation and cooling systems, and core protection system. A case study for this topic concerns the PVNGS essential spray pond fouling.

6. Integrated Plant Operations - provides students with overall knowledge of plant equipment operation and assists them in developing a better understanding of transients and accident sequences applicable to nuclear power plant operation.

7. Materials Corrosion, and Chemical and Volume Control - chemical and volume control of the reactor coolant system can have far-reaching effects on materials, including issues with stress corrosion cracking (SCC). Case studies include the reactor vessel head degradation at the Davis-Besse Nuclear Power Station ${ }^{7}$ and the leakage from reactor vessel lower head at South Texas Project Unit 1.

8. Instrumentation and Controls - there is considerable regulatory interest in digital instrumentation and controls due to proposed retrofits to existing nuclear power plants and the plans for all-digital systems in the new plants ${ }^{8}$. The industry is presently undertaking significant efforts in this area and is expected to continue to do so into the near future given the issues (e.g., common cause failure due to software errors) that present themselves in qualifying digital technology for nuclear reactor safety systems. The recent process behind and the installation of digital feedwater controllers at PVNGS makes an excellent case study for this topic.

9. Human Factors - examines issues such as human performance in engineering, shift work impact and fitness-for-duty. Control room modifications and the use of control room simulators are also addressed.

10. Plant Modifications - clearly retrofits and modifications to the plant require re-analysis of impacted features. A very good case study for the nuclear power industry is the process of power uprating. Part of the reason for using this as a case study is that there are three different levels of power uprates: (1) measurement uncertainty recapture $(<2 \%$ power uprating) for implementation of enhanced techniques for computing reactor power using more accurate flow sensors, (2) stretch power uprates $(<7 \%)$ using changes to instrumentation setpoints, and (3) extended power uprates $(<20 \%)$ in the case of significant equipment modifications. Increasingly larger uprates require an increasing amount of reanalysis due to the greater impact plant-wide. 
11. Radioactive Waste Generation and Effluent Monitoring - the effectiveness of plant operations has a direct impact on the generation of low-level wastes and the concomitant need for monitoring effluents from the plant. A current topic in the nuclear industry is the contamination of groundwater via unintended releases of tritium.

12. Industry Events - addresses current topics and operating experience in the nuclear power industry, including reactor license renewal, and new reactor licensing. A current issue regarding emergency systems is whether debris can accumulate on the containment sump screens in PWRs from a loss-of-coolant accident. Such an occurrence would impede the return water flow to the low-pressure emergency core cooling and containment spray systems. Students review operating event reports (LERs) and the processes used to mitigate or correct the incident, and formulate solutions to ensure that the event or incident does not reoccur.

13. Security - the security aspects of nuclear power plant operations can be addressed within the course in a generic form without the need to reveal sensitive plant-specific information. However, the nationally publicized incident at PVNGS in which a pipe bomb was discovered in the truck of a contract worker can be used as a case study. The pipe bomb was found during a routine screening at the security checkpoint of the plant-site entrancethis incident resulted in an unusual event being declared in November 2007.

14. Grid Disturbances - in examining the interaction of various systems on power plant operations, another impact point is the affect that disturbances in the electric power system have on the power plant. With the increasing desire to add intermittent green energy sources such solar and wind, there is a possibility of more grid disturbances such as that experienced by Texas in February 2008.

15. Exams - both a midterm and final exam are administered. These exams not only allow the instructor to evaluate the knowledge and proficiency of the student, but also to assess (and improve) the course itself.

The overall course grading is based on homework (25\%), mini projects (30\%), a midterm exam $(20 \%)$ and the final exam $(25 \%)$.

\section{Lessons Learned}

The successful development of any course can pose challenges, and opportunities. Having the support of upper-level utility management in such an endeavor is clearly important. In this project, there was buy-in by the Vice President of Operations at PVNGS, who affirmed the commitment of Arizona Public Service to this project early on. A few of the lessons learned, so far, from this course development are discussed below.

Although sometimes costly, most students seem to prefer to have a dedicated textbook that is used in a course, in contrast to course notes that are sometimes limited in content and in outline format. A challenge is the fact that with the reduction in nuclear engineering programs across the U.S. over the past 20 years, the selection of textbooks, in general, has diminished, much less the availability of a textbook appropriate to such a unique course. One textbook considered is Nuclear Engineering: Theory and Technology of Commercial Nuclear Power, $2^{\text {nd }}$ Edition by R. A. Knief. Although this 770-page book is in print through the American Nuclear Society with a copyright date of 2008, this edition was originally published by Taylor \& Francis in 1992; thus 
making the material older than it might first appear. Another option under consideration is the development of course-specific reading materials with the cooperation between the university faculty and the industrial partners at the PVNGS. A final decision on this aspect has yet to be made, in part, due to copyright considerations regarding the latter option.

One of the unexpected delays in this project was the time required for the university and utility attorneys to negotiate an acceptable non-disclosure agreement (NDA). In our case, the NDA ended up taking about three months to complete. Without going into details, it turned out that prior (negative) experience with a university faculty member resulted in some unexpected issues and (valid) concerns from the utility.

Probably the most important lessons learned are centered around the logistics of the video recording. There are two separate categories of video recording: (1) various equipment and systems around the power plant, and (2) the actual course lectures. The former video recordings are made for insertion into the lectures where the video is relevant to the subject material being addressed that day. In this case, we were fortunate that the PVNGS media group was able to assist in making these recordings, but there was delay time for university receipt due to the utility need to verify that no security-related concerns were raised by the public release of the material.

The latter, lecture recordings presented several possibilities for the recordings as our plans called for utilizing the cognizant power plant personnel to present the actual lecture material for the subject matter for which they are experts. Questions arose such as whether the plant personnel should be brought to the university, or portable video recording equipment should be transported to the power plant. Bringing the utility personnel to the university presented the benefit that the technology available in the mediated classroom was better, but the travel distance and time requires greater commitment from the utility. For example, in terms of technology in the recording room, the university facilities have a writing pad and/or document camera, whereas the power plant training room only provides a whiteboard which results in low-quality text and graphic recordings. Both facilities had computer and projection equipment, but the power plant setting was absent of a method to record the computer output in synch with recording the instructor, but that was solvable using a portable media center from the university. In either case, we also considered whether the presenter would lecture to an empty (class)room or whether we should populate the room with a few "students" (either true students or mock students) whose questions would also become part of the permanent recordings. The power plant personnel were more accustomed to having an interactive class; therefore, the latter approach was favored.

Another option for lecture recording was to record relevant segments from some in-house training courses at the power plant. In this case, the plant engineers taking the training course provide a natural audience of students, but at the nuclear plant, a microphone would have to be passed around to any students in order to record their questions. In this option, a two-person team can be used to record only the class hours that are considered relevant: one person operates the camera to follow the instructor; and the second person manages a portable media recorder that takes the camera output along with the computer output (e.g., PowerPoint slides) and combines them together. However, in the end, the recorded video has to be edited for content and length of play; thus requiring both a faculty member and a technical support person (video editor) to be involved in the post-production processing. To avoid this possibility of generating 
an overwhelming amount of video recordings that might need to be reviewed, a scripted class was favored.

\section{Summary}

The development of an entire online course on interdisciplinary nuclear power operations has been described. The Interdisciplinary Nuclear Power Operations course is a unique industryuniversity team-taught course with support from the Palo Verde Nuclear Generating Station (PVNGS). The impending revival of nuclear power in the U.S. and the fact that engineers from a variety of engineering fields staff nuclear power plants is an impetus for creating such a course.

\section{Acknowledgment}

This work presented herein was sponsored by the U.S. Nuclear Regulatory Commission under grant number NRC-38-08-905.

\section{Bibliography}

1. U.S. NRC, "Expected New Nuclear Power Plant Applications," December 17, 2008, available online at http://www.nrc.gov/reactors/new-reactors.html.

2. E. M. Blake, "Watching and waiting for Washington," Nuclear News, vol. 52, no. 1, pp. 35-39, January 2009.

3. K. E. Holbert, "Signs of a nuclear revival in the United States?," Ninth IASTED International Conference on Power and Energy Systems, Clearwater, FL, Jan. 3-5, 2007, pp. 357-362.

4. Dale E. Klein, "Preparing for new plant licensing and construction," Platts Third Annual Nuclear Energy Conference, Washington D.C., Feb. 8-9, 2007.

5. N. A. Wogman, L. J. Bond, A. E. Waltar, R. E. Leber, "The nuclear education and staffing challenge: Rebuilding critical skills in nuclear science and technology," Journal of Radioanalytical and Nuclear Chemistry, vol. 263, no. 1, pp. 137-143, 2005.

6. D. Ross, "Draining the talent pool," Power Engineering, vol. 109, no. 5, pp. 46-50, May 2005.

7. U.S. NRC, "Davis-Besse Reactor Pressure Vessel Head Degradation," NUREG/BR-0353, Rev.1, Aug. 2008.

8. R. T. Wood et al. "Advanced Reactor Licensing: Experience with Digital I\&C Technology in Evolutionary Plants,” NUREG/CR-6842, April 2004. 